\title{
A constitutional critique on the regulations relating to artificial fertilisation of persons
}

\author{
D W Jordaan, BLC, LLB, MPPS, PGDipSI, PhD \\ School of Law, Howard College, University of KwaZulu-Natal, Durban, South Africa
}

Corresponding author: D W Jordaan (JordaanD@ukzn.ac.za)

\begin{abstract}
It is constitutionally impermissible for legislation to over-medicalise, that is, to legally enforce medical influence and supervision over certain actions, without good reason why such medical influence and supervision are required. Various parts of the regulations relating to artificial fertilisation of persons made in terms of the National Health Act over-medicalise aspects of artificial fertilisation and gamete donation. These offending parts of the regulations are accordingly unconstitutional and invalid. The article calls for a thorough review of the regulations from a constitutional perspective.
\end{abstract}

SAfr J Bioethics Law 2017;10(1):29-31. DOI:10.7196/SAJBL.2017.v10i1.497

It is a basic constitutional requirement that all legislation must be rational rather than arbitrary. ${ }^{[1]}$ Generally, the rationality requirement states that government must be able to substantiate any legislative provision, and that the reasons tendered in substantiation must be aligned with our Constitution ${ }^{[2]}$ and its underlying values; in the absence of such reasons, a legislative provision would be unconstitutional and invalid. More specifically, the rationality requirement requires that the rules of logic must be applied to any substantiation of a legislative provision. For instance, a conclusion that is based on a generalisation is illogical and would not pass the rationality requirement.

This article considers the regulations relating to artificial fertilisation of persons ('the regulations') ${ }^{[3]}$ made in terms of the National Health Act No. 61 of $2003{ }^{[4]}$ I show that the regulations are premised on the notion that all gamete donation and all artificial fertilisation should involve a healthcare practitioner - in particular, a specialist in reproductive medicine. I call into question the rationality of this premise. I suggest that a more rational premise on which to build future regulations would be to recognise that certain kinds of gamete donation and certain kinds of artificial fertilisation require the involvement of healthcare practitioners for good reasons; but also to recognise that other kinds of gamete donation and artificial fertilisation do not require the involvement of healthcare practitioners, and hence do not require the law to enforce such involvement.

\section{Hypothetical case study}

In the following hypothetical case study, a lesbian couple, A and B, wish to have a child. They decide that $B$ should become pregnant with the sperm of C, A's twin brother. C agrees to provide his sperm. They agree that the child will be in the care and under the guardianship of $A$ and $B$, and that $C$ will enjoy contact rights with the child and will be the child's godfather. They Google 'how to inseminate at home', quickly get an answer (in brief, masturbation followed by insertion of the semen by syringe), and follow the steps. B becomes pregnant, and after 9 months gives birth to a healthy baby girl, D. On A and
$B$ 's request, both $A$ and $B$ are indicated as D's parents on her birth certificate..$^{[5]}$ Although one's moral intuition would suggest that $A, B$ and $C$ have done nothing wrong - they were living their lives and did not harm anyone - the regulations in their current form criminalise their actions.

\section{The regulations}

The regulations' definition of artificial fertilisation reads as follows (reg. 1):

'Artificial fertilisation' means the introduction other than [by] natural means of a male gamete or gametes into the internal reproductive organs of a female person for the purpose of human reproduction and includes artificial insemination, in vitro fertilisation, gamete intrafallopian tube transfer, embryo intrafallopian transfer or intracytoplasmic sperm injection'.

Key to understanding the provisions of the regulations is the definition of a 'competent person', which reads as follows (reg. 1):

"competent person' means a medical practitioner registered with the Health Professions Council of South Africa (HPCSA) with expertise in specialist gynaecologist [sic] and sub-specialist in Reproductive Medicine, or a trainee in Reproductive Medicine in a training unit under the supervision of a registered HPCSA sub-specialist'.

All the kinds of artificial fertilisation must be effected by a 'competent person' (reg. 10(2)): 'Only a competent person may effect artificial fertilisation. Accordingly, it is clear that A, B, and C's actions are in contravention of the regulations. This is not a trivial matter, given that contravention of the regulations is criminalised (reg. 21):

'Any person who contravenes or fails to comply with any provision of these regulations commits an offence and is liable on conviction to a fine or imprisonment for a period not exceeding 10 years, or to both such fine and imprisonment'.

$B$ (who was artificially fertilised) can be prosecuted as perpetrator, and A (B's partner, who involved her brother, $C$ ) and $C$ (the sperm donor) can be prosecuted at least as accomplices, given that they actively assisted $\mathrm{B}$, the perpetrator. 
This is not the only crime for which A, B, and C can be prosecuted. The regulations also stipulate that a 'competent person' must be involved in the sperm donation (reg. 4(1)):

'No person, except a competent person, may remove or withdraw a gamete or cause a gamete to be removed or withdrawn, from the body of a gamete donor for the purpose of artificial fertilisation'.

The terminology 'removed or withdrawn' is not only applicable to an egg donor, but to any gamete donor in general. This is made clear by the definition of 'gamete donor' that employs this terminology (reg. 1):

"'Gamete donor" means a living person from whose body a gamete or gametes are removed or withdrawn, for the purpose of artificial fertilisation.'

Accordingly, given that $A, B$, and $C$ all caused sperm to the donated without the involvement of a 'competent person', they are all liable to be prosecuted on this additional criminal charge as well.

Involving a 'competent person' would only have been the first step towards legal compliance, as the regulations require that the 'competent person' must, before donation, obtain several pieces of information from the donor and ensure that, among other things, the donor has recently undergone a test for sexually transmitted diseases (STDs) (reg. 8(g)). Moreover, in cases where the donor and the intended mother are known to each other, both parties must submit to psychological evaluation (reg. 8(j)).

\section{Discussion}

Zola ${ }^{[6]}$ defines 'medicalisation' as the 'process whereby more and more of everyday life has come under medical dominion, influence and supervision'. I suggest that the way in which the regulations deal with artificial insemination (Al), with gamete donation by a known donor, and with sperm donation is a case of over-medicalisation. The problem with the regulations is that they fail to treat different kinds of artificial fertilisation and gamete donation differently.

\section{Artificial fertilisation}

The definition of artificial fertilisation is broad and encompasses a number of techniques. These range from a technique such as intracytoplasmic sperm injection, that requires among other things an embryology laboratory and skilled embryologists, to - on the other side of the spectrum - Al that can be done at home, ${ }^{[7]}$ as per the hypothetical case study. There is no reason to legally require that the entire spectrum of artificial fertilisation techniques be medicalised.

A possible counter-argument may be that there is a risk that diseases, such as HIV, could be transmitted through Al. ${ }^{[8]}$ However, the risk of such transmission is not sufficient reason to legally medicalise Al. If it were sufficient reason, unprotected consensual sexual intercourse should be medicalised for the same reason. The state surely has an interest in avoiding the transmission of disease, but it would be an obvious infringement on persons' privacy to require the involvement of a 'competent person' (or any other type of healthcare practitioner) each time a person decides to have sexual intercourse. The state has other means at its disposal to promote the avoidance of the transmission of disease, such as awareness campaigns. The same rationale applies to disease in the case of $\mathrm{Al}$.

Not only are privacy rights at stake, but also the right to establish a family (which is part of the right to human dignity), ${ }_{r^{[9]}}$ and the right to protection against unfair discrimination. To add to the case study: consider a fertile heterosexual couple $E$ and $F$, who are allowed to procreate without being legally obliged to spend time and money on having a 'competent person' involved in any way. Why should A, B and C be expected to expend time and money on such a 'competent person' to perform the Al if they can perform the procedure themselves, in the privacy and comfort of home? The regulations obstruct the right of persons who use $\mathrm{Al}$ to establish a family; moreover, the regulations make it more difficult for lesbian persons to establish a family, which constitutes unfair discrimination.

\section{Gamete donation}

Gamete donation can be categorised along two main lines: sperm v. eggs, and known donor v. unknown donor. I discuss the latter differentiation first. In cases where an intended mother must rely on an unknown donor, it makes sense - in the interests of the intended mother - to require the donor to provide relevant information, including the results of relevant medical tests, to the 'competent person'. Such information is a substitute for knowing the donor personally. However, when the donor is known to the intended mother, the rationale for such information in principle falls away. Consider, for instance, an intended mother who cannot conceive sexually with her husband, but who intends to use her husband's sperm for in vitro fertilisation. Had she been fertile, she could have consented to using her husband's sperm via sexual intercourse without her husband first having to provide certain information. This raises the issue of equal treatment of fertile and infertile persons. While it can be argued that having access to her husband's STD test results is to the benefit of the intended mother, this is an excessively paternalistic way to treat consenting adults. Given that the intended mother knows her husband (in the sense that he is not an unknown anonymous donor), she can request him to undergo STD tests as a precondition to using his sperm - irrespective of whether the couple plans to procreate via sexual intercourse or via artificial means. A rational approach would therefore dictate that, in the case of a donor that is known to the intended mother, the requirement that such a known donor must provide certain information to the 'competent person' should be suspended.

Instead of suspending this legal requirement, the regulations do the exact opposite, by in addition requiring that both the donor and the intended mother must submit to psychological evaluation. This is a clear case of over-medicalisation. With reference to the case study, why should $A, B$ and $C$ be legally required to submit to (and spend the time and money on) an evaluation by a psychologist, if $E$ and $F$ ( $a$ fertile heterosexual couple) are allowed to procreate without having to be psychologically evaluated? The fact that in the case of a donor that is known to the intended mother, the regulations still require that such a known donor must provide certain information to the 'competent person' constitutes arbitrary legislation and unfair discrimination against lesbian persons; the additional requirement of the psychological evaluation adds fuel to the fire of unconstitutionality.

A further weakness of the regulations is that they fail to treat egg donation and sperm donation differently. While the process of retrieving eggs is a medical process - minor surgery - the retrieval of sperm for donation, by means of masturbation, is non-medical in nature. Accordingly, while egg donation requires the involvement of a relevantly qualified healthcare practitioner to effect the donation, 
sperm donation does not require such involvement. In fact, a sperm donor's right to privacy may require the opposite, namely that no person - including a healthcare practitioner - may be in the room while he is masturbating to donate sperm. There is no reason to legally require that sperm donation should be medicalised.

A possible counter-argument may be that the number of offspring from a single sperm donor should be limited, hence the need to involve a'competent person'. This counter-argument is paternalistic, as it assumes that sperm donors cannot abide by the law (the offspring limitation) by themselves, and need a healthcare practitioner to ensure such compliance. Such paternalism is clearly untenable in our constitutional dispensation that ascribes to the value of autonomy. The fact that the regulations make the involvement of a 'competent person' incumbent for sperm donation is again a case of overmedicalisation.

\section{Conclusion}

My argument should not be understood as advising against the involvement of a healthcare practitioner at the behest of the intended mother and the donor. This properly falls within the domain of autonomy of the intended mother and the donor. What I am arguing against is the over-medicalisation of artificial fertilisation and gamete donation - legally enforcing medical influence and supervision over artificial fertilisation and gamete donation without good (constitutionally aligned) reason. In other words, A, B and C should be free to make use of healthcare practitioners to assist them if they so choose. However, the current regime that legally forces them and all persons who are similarly situated - to submit to various kinds of medical influence and supervision is clearly without good reason, and hence unconstitutional and invalid.

In this article I have focused on the logical error of generalisation regarding artificial fertilisation techniques and the kinds of gamete donation that permeate the regulations, and the legal consequences such that the relevant aspects of the regulations that were discussed above fail the basic rationality requirement of the Constitution. I should note that this article is not exhaustive of all the unconstitutional and generally problematic aspects of the regulations. The regulations are in need of thorough review - especially from a constitutional perspective.

1. Pharmaceutical Manufacturers Association of South Africa and Another: In re Ex Parte President of the Republic of South Africa and Others, 2000 (2) SA 674, paras 84-86.

2. Constitution of the Republic of South Africa, 1996.

3. South Africa. National Health Act No. 61 of 2003. Regulations Relating to Artificial Fertilisation of Persons. GN R1165 GG 40312, 30 September 2016.

4. The National Health Act No. 61 of 2003.

5. J and Another v Director General, Department of Home Affairs and Others 2003 (5) SA 621 (CC).

6. Zola IK. Socio-Medical Inquiries. Philadelphia: Temple University Press, 1983;295.

7. Wikler D, Wikler NJ. Turkey-baster babies: The demedicalization of artificial insemination. Milbank Q 1991;69(1):5-40. http://dx.doi.org/10.2307/3350118

8. Guinan ME. Artificial insemination by donor: Safety and secrecy. JAMA 1995;273(11):890-891. http://dx.doi.org/jama.1995.03520350072033

9. Certification of the Constitution of the Republic of South Africa, 1996, 1996 (4) SA 744 (CC), para 100. 